\title{
Enhancing Concept Development of Preschoolers through Intervention
}

\author{
Anju Manocha and Darshan Narang \\ Department of Human Development and Family Studies, College of Home Science, \\ C. C. S. H. A. University, Hisar 125 004, Haryana, India
}

KEYWORDS Concept Development. Applications. Experimental. Control. Pretesing and Posttesting

\begin{abstract}
The present investigation was carried out with 3-5 year old children from villages of Hisar district of Haryana state. The existing status of concept development of children was measured during pretesting and the sample of 120 children was divided into two study groups to see the impact of intervention.. The results revealed that the concept development status improved in both the study groups irrespective of the intervention exposure. But $\mathrm{F}$ values of 76.13 and 84.11 on Form ' $\mathrm{C}$ ' and 'Applications' respectively during Post-testing revealed significant differences in the performance of control and experimental group children. The performance of control and experimental group children on concept development during Follow-up also varied significantly as revealed by $\mathrm{F}$ values of 65.93 and 50.19 on Form C and 'Applications' respectively. To counter the gain of control group, achievement score of experimental group children was calculated. The achievement score of experimental group children's performance on Form 'C' and 'Applications' came out to be 9.49 and 5.04 at Post-testing and corresponding figures at Follow-up were 7.45 and 3.69 respectively.
\end{abstract}

\section{INTRODUCTION}

Concepts are regarded as the fabric of mental life; they serve to carve up the person's world into functional units. A concept is the basic unit of all types of learning. Human beings from the infancy to old age learn new concepts and use old concept in new situations of their daily life. Individuals differ in their level of concept formation on the basis of their age, intelligence and experience. Kagan (1987) emphasizing the importance of concepts in life writes that concepts are fundamental agents to intellectual work. The process of concept formation emerges from a big, buzzing, blooming, confusion in which the child is born. The child is endowed with certain biological inheritance at the time of his birth. $\mathrm{He}$ gets the knowledge of the external world through sense organs, which are the gateways of knowledge. With any child some concepts may be fully and accurately developed, others only partially developed, and still others quite inaccurate. Differences in particular areas appear from one child to the next depending on developmental level and experiences. Since certain abilities of children are directly related with the environment in which they live, cultural variations make them to differ from children of some other cultural settings (Bronfenbrenner, 1989). Then emphasis should start at an early stage, as these are critical years in a child's span since the rate of development is more rapid than at any other stage of development. To develop to his or her full potentials, a child, particularly in these years needs a stimulating environment. The parents, who are illiterate, are not able to interact effectively with the children or help them to develop appropriate cognitive skills. Development of the child is the outcome of combined and cohesive impact of heredity and environment whereas environment is envisioned as a series of vested structures that extend beyond the home, school and neighborhood. Environment has a powerful impact on the competence development of the child. Many researches on cognitive development have proved that early childhood stimulation attempts are providing learning experiences to the child so as to enhance his/her conceptual development. These experiences demand a close interaction between the child and parents. Many psychologists reported importance of environmental factors in influencing the early development of the child.

\section{MATERIALS AND METHODS}

In order to carry out an intensive study, four villages of Hisar district of Haryana state was selected purposively as the locale of study. The purpose of selection was easy access and convenience. Two of these villages served as control group villages and rest two were the experimental group villages. From each of the 
experimental group village, 15 boys and 15 girls, who obtained lower conceptual scores relatively, were selected for intervention. So, experimental group comprised of 60 children in total, i.e. 30 from each experimental village. Similar procedure was followed for the selection of 60 children of control group making a total of 120 children as subjects. All these subjects (120 children) were pretested for judging their existing status of conceptual development. For the present study, the level of cognitive concepts of preschool children was measured in terms of child's level of performance on commonly used basic concepts using Boehm's Test of Basic Concepts- Revised (1986).

The subjects from experimental group only (60 children) were exposed to intervention program for 16 weeks whereas control group was left unexposed to any kind of such program. So the subjects from experimental group only served as sample. The program took into account the children's cognitive experiences within the family including family interaction, play opportunities, literature available and exposure to mass media.

To assess the impact of intervention, Posttesting, after a period of 4 weeks of completion of intervention was conducted on all subjects from experimental as well as control group for their conceptual enhancement. To see the relatively permanent impact of intervention, Follow-up testing was carried out on the same sample after a gap of 16 weeks for conceptual development.

\section{RESULTS AND DISCUSSION}

The children were assessed for their mastery of the basic concepts that are both fundamental to understanding verbal instruction and essential for early achievement. This may be used to identify children with basic concept deficiencies, and also to identify concept areas that should be targeted for further instruction. Two alternate forms of Bohem-R are available, Form ' $C$ ' and Form ' $\mathrm{D}$ '. The test has three parts, Form ' $C$ '. Form 'D' and 'Applications'. Form ' $C$ ' and Form ' $\mathrm{D}$ ' are parallel forms, which can be used interchangeably. The scores of children on Form $\mathrm{C}$ and Applications are as follows. There was gain in scores of concept development at both the testings in control as well as experimental group children (Table1). ANOVA was run using groups as independent factor and mean gain in Form ' $\mathrm{C}$ ' and 'Applications' as dependent factor.
As presented in Table 1, Duncan Multiple range test revealed that for the control group, mean gain in Form ' $\mathrm{C}$ ' $(\mathrm{M}=3.79)$ and 'Applications' (M=2.42) were lower than the gain in these aspects of experimental group, $\mathrm{M}=13.28$ and 7.46 respectively at Post-testing.

Table 1: Mean gain in concept development of control and experimental group children at Posttesting.

\begin{tabular}{lcccc}
\hline S. & Components & \multicolumn{2}{c}{ Mean gain } & 'F' \\
\cline { 2 - 3 } No. $\quad$ of BTBC & Control & Experiment & \\
\hline 1. & Form 'C' & 3.79 & 13.28 & $76.13 * *$ \\
2. 'Applications' & 2.42 & 7.46 & $84.11^{*} *$ \\
\hline Significant at ** $\mathrm{p}<0.01$ & &
\end{tabular}

Similarly at Follow-up testing, control as well as experimental group showed an improvement in concept development from the Pre-testing scores as depicted in Table 2. The mean gain in control group on performance of Form ' $\mathrm{C}$ ' and 'Applications' was 3.97 and 2.44 respectively and the respective figures of experimental group were 11.42 and 6.13. So, the concept development status improved in both the study groups irrespective of the intervention exposure. But relatively higher mean gains of experimental group on performance of Form ' $\mathrm{C}$ ' as well as 'Applications' of BTBC proved the impact of intervention package on concept development of children.

Table 2: Mean gain in concept development of control and experimental group children at Follow-up.

\begin{tabular}{lcccc}
\hline S. $\begin{array}{c}\text { Components } \\
\text { No. of BTBC }\end{array}$ & \multicolumn{2}{c}{ Mean gain } & 'F' \\
\cline { 2 - 4 } & Control & Experiment & \\
\hline 1. Form 'C' & 3.97 & 11.42 & $65.93^{* *}$ \\
2. 'Applications' & 2.44 & 6.13 & $50.19^{*}$ \\
\hline
\end{tabular}

Significant at $* * \mathrm{p}<0.01$

ANOVA was also run to see the significance of differences in control and experimental group performance. The $F$ values of 76.13 and 84.11 on Form 'C' and 'Applications' respectively during Post-testing revealed significant differences in the performance of control and experimental group children. The performance of control and experimental group children on concept development during Follow-up also varied significantly as revealed by $\mathrm{F}$ values of 65.93 and 50.19 on Form C and 'Applications' respectively. 
Thus, it can be said that no doubt the concepts improved with age in children due to developmental outcomes and certain other factors that were beyond control. But the higher development of concepts in experimental group children may be attributed to their exposure to the intervention package. Higher gains of experimental group at Follow up stage further indicate that the exposure to intervention program had relatively long lasting impact on concept development.

\section{Achievement Score of Concept Development}

As mentioned earlier, there was gain in scores on components of concept development in control as well as experimental group, so to counter the gain of control group children, achievement score was computed. Table 3 and 4 depict the achievement score of experimental group children on concept development at Posttesting and Follow-up respectively.

Achievement score of experimental group children was calculated by deducting mean gains of control group from the mean gains of experimental group at Post-testing and Followup. The developmental outcomes or natural gain that occurred in control group was due to occur in experimental group children as well. So, the net gain or achievement score of experimental group was worked out by taking the natural gain into consideration. This was the actual impact of intervention package on concept development of children. The achievement score of experimental group children's performance on Form ' $\mathrm{C}$ ' and 'Applications' came out to be 9.49 and 5.04 (Table 3) at Post-testing and corresponding figures at Follow-up were 7.45 and 3.69 respectively (Table 4$)$.

This revealed that improvement in concept development status of experimental group children was much higher than the improvement in control group children. The results of the present study are in consonance with the

Table 3: Achievement score of experimental group children at Post-testing on concept development $(\mathbf{N}=120)$

\begin{tabular}{lllrc}
\hline $\begin{array}{l}\text { S. } \\
\text { No. }\end{array}$ & $\begin{array}{l}\text { Components } \\
\text { of BTBC }\end{array}$ & $\begin{array}{l}\text { Gain in } \\
\text { control } \\
\text { group }\end{array}$ & $\begin{array}{l}\text { Gain in } \\
\text { Expt. } \\
\text { group }\end{array}$ & $\begin{array}{l}\text { Achievement } \\
\text { socre of exp. } \\
\text { group }\end{array}$ \\
\hline 1. & Form 'C' & 3.79 & 13.28 & 9.49 \\
2. & 'Applications' & 2.42 & 7.46 & 5.04 \\
\hline
\end{tabular}

Table 4: Achievement score of experimental group children at Follow-up on concept development (N=120)

\begin{tabular}{llccc}
\hline $\begin{array}{l}\text { S. } \\
\text { No. }\end{array}$ & $\begin{array}{l}\text { of BTBC } \\
\text { of }\end{array}$ & $\begin{array}{l}\text { Gain in } \\
\text { control } \\
\text { group }\end{array}$ & $\begin{array}{l}\text { Gain in } \\
\text { Expt. } \\
\text { group }\end{array}$ & $\begin{array}{l}\text { Achievement } \\
\text { socre of exp. } \\
\text { group }\end{array}$ \\
\hline 1. Form 'C' & 3.97 & 11.42 & 7.45 \\
2. 'Applications' & 2.44 & 6.13 & 3.69 \\
\hline
\end{tabular}

findings of Rani (2001) who while working out gain in cognitive aspects calculated net gain in experimental group to find out the gain due to intervention package and found that net gain in experimental group came out to be significantly higher

It can thus be concluded that the mean difference in concept development of both the groups which were negligible at Pre-testing stage rose by many folds at Post-testing. This indicates higher mean scores of experimental group children after their exposure to intervention. Though gain was observed in the concept development of control group children as indicated by the ' $t$ ' values but higher ' $t$ ' values for experimental group indicate that these children performed much better and this improvement can be attributed to intervention provided to them and mothers. Mothers were stimulated who further motivated the children and made them actively learn for their enhancement of conceptual development. Although the control group children did not receive any intervention, there was gain in their scores of concept development. This gain might be a natural gain. Whatever could be the reasons, these factors might have also been operating behind the gain in experimental group. Dhanda (2000) in an intervention study also found that post testing scores of control as well as experimental group increased.

However, improvement in control group might be normal development over a course of time which could not be controlled. The results of present study are in line with the findings of Kaliramna (1999), Dhanda (2000) and Sandhu (2001) who concluded that at pretesing stage both the groups were almost similar in cognitive and language performance. At Ist and 2nd posttesting stage, significant differences were observed as intervention group performed much higher than those of control group, which means the gain was higher in intervention group. The reason may be coverage of cognitive and 
language aspects by researcher with maximum use of related literature and various teaching aids which led to improvement of knowledge on these concepts.

The study further reveals that there were significant differences in Post-testing and Follow-up mean scores of control and experimental groups. Mean scores of experimental group children were significantly higher than those of control group. These results are in line with the findings of previous research (Lamm and Epstein, 1997). These authors examined the effect of intervention program on the development and functioning of preschoolers. The cognitive development level was assessed. An experimental research design was used in which half children received the intervention and half children served as controls. Analysis revealed significant improvement in acquisition of cognitive skills for sample in the experimental group although control group sample also acquired the skills in due course of time. They were able to bring improvement in children by imparting intervention programme.

The present study clearly demonstrates that enhancement in concept development of experimental group was significantly higher. The reason is no doubt the exposure of experimental group children and mothers to the intervention package. During intervention, mothers were also provided information, how they could foster the concept development of their children, alongwith the exposure to children by researcher. Thus, two factors simultaneously worked for conceptual enhancement of children. Anand Lakshmi (1990) also reported that an intervention program was most likely to succeed if it included involvement and interest of mothers. Kaliramna (1999) too involved mothers in intervention programme for young children and found that there was significant improvement in cognitive development of children.

It is apparent from the above results that there was gain in concept development of children in both the control and experimental group. Though the control group did not receive any intervention exposure, still there was a gain in concept development. Though development occurred in both the study groups but mean gain and achievement score of experimental group children suggested better performance of experimental group children on concept development. These results are also supported by a study conducted by Rani (2001) who mean gain in different aspects of cognition in three study groups and found significantly higher mean gain in all these aspects of experimental group children. It is therefore concluded from the results that an intervention program caused significant improvement in the concept development status of experimental group children which included their performance on Form 'C' and 'Applications'. Saharan (1993) too observed similar results and revealed that a need based intervention program, if suitably designed and implemented can cause dramatic improvement in language skills of pre-school children. Corroborating the results of present study, Kumari (1994) also reported that intervention program enhanced cognitive abilities of children. After implementation of intervention program majority of children achieved medium to high level of cognitive abilities.

Thus it can be concluded that preschool children who received intervention exposure show significant gains in conceptual development as compared to control group children from similar backgrounds.

\section{REFERENCES}

Anand, Lakshmi, S.: Towards enhancing cognitive development: Stimulating play in infancy. In: Research in Child Development. U.K. Bevli. NCERT, New Delhi (1990).

Boehm, A.E.: Boehm's Test of Basic Concepts R. The Psychological Corporation, New York (1986).

Bronfenbrenner, U.: Ecological systems theory. Annals of Child Development, 6:187-251 (1989).

Dhanda, Bimla. Intervention Program for Mothers of Babies with Development Deficiencies. Unpublished Ph.D. Dissertation in Child Development, COHS, CCS Haryana Agricultural University, Hisar, India (2000).

Kaliraman, Ashu: Home-based Intervention Program on Cognition for Parents of Preschoolers (3 to 4 yrs). Unpublished Ph.D. Dissertation in Child Development, COHS, CCS Haryana Agricultural University, Hisar, India (1999).

Kagan, J.: Introduction. In: The Emergence of Morality in Young Children. J. Ragan and S. Lamb (Eds.). University of Chicago Press, Chicago (1987).

Kendalla, Philip, C. and Braswell: Methodology and cognitive behavioral assessment. Behavioral Psychotherapy, 22(4): 1283-1300 (1996).

Kumari, L. Impact of Intervention Programmes on Cognitive Abilities of Preschoolers. An Experi-mental Study. Unpublished. M.Sc. Dissertation in Child Development, COHS, CCS Haryana Agricultural University, Hisar, India (1994).

Lamm, O. and Epstein, R.: Dichotic listening in children. The reflection of verbal and attentional changes with age. Journal of Experimental Psychology, 65(1): 25-42 (1997). 
Rani, Usha: Impact of Some Environmental Stimulating Packages on Cognitive Development of 4-6 Years Old Pre-School Children. Unpublished Ph.D. Thesis in Department of Education, Kurukshetra University, Kurukshetra. India (2001)

Sandhu, S.: Cognition and Language Intervention Program for Two to Three Years Old Children.
Unpublished Ph.D. Thesis in Child Development, COHS, CCS Haryana Agricultural University, Hisar, India (2001).

Saharan, R.: Language Development among Children of 3-4 yrs of Age. Unpublished Ph.D. Dissertation in Child Development, COHS, CCS Haryana Agricultural University, Hisar, India (1993). 